\title{
Being and becoming a 'good' qualitative researcher? Liminality and the risk of limbo
}

\begin{tabular}{|r|l|}
\hline Journal: & Qualitative Research in Organizations and Management \\
\hline Manuscript ID & QROM-04-2017-1523.R2 \\
\hline Manuscript Type: & Original Article \\
\hline Keywords: & PhD, Early-career, Identity state, Liminality, Limbo, Reflexivity \\
\hline \multicolumn{2}{|l}{} \\
\hline
\end{tabular}

SCHOLARONE ${ }^{\text {m }}$

Manuscripts 


\title{
Being and becoming a 'good' qualitative researcher? Liminality and the risk of limbo
}

\begin{abstract}
Purpose - The purpose of this paper is to re-conceptualise 'good' qualitative research by discussing the intersection between 'good' qualitative research and different identity states of 'good' qualitative researcher. It uses the anthropological concept of liminality and related concept of limbo to help illustrate the implications of this intersection.
\end{abstract}

Design/methodology/approach - A reflexive and personal confessional account is provided of my 'living in' the liminal transition of the identity states of full-time $\mathrm{PhD}$ student to fulltime early career researcher, questioning my experiences in relation to others and the implications for the social construction of 'good' qualitative research.

Findings - 'Good' qualitative research is not just what to do but how to be. ' $\mathrm{PhD}$ student' is a defined and temporary transitional liminal identity state. It has a clear point of separation (acceptance and registration of student status) and aggregation ('good' qualitative research signed of through thesis and viva). Contrasting with this is the 'early career researcher' identity state, any point of aggregation towards 'established researcher' is predicated on the unpredictability of publication and delivering impact indicators.

Originality/value - The paper demonstrates unsettling and in-betweenness of 'good' qualitative research intersecting with the experience and composition of being a 'good' qualitative researcher in the academy. It is important for debates regarding the qualities of academic development from $\mathrm{PhD}$ student to established researcher.

Keywords Early career, Identity state, Limbo, Liminality, PhD, Reflexivity

Paper type Research Paper 


\section{Being and becoming a 'good' qualitative researcher? Liminality and the risk of limbo}

\section{Starting thoughts}

In this paper, I reflexively examine my own experiences in becoming and being a 'good' qualitative researcher in relation to doing 'good' qualitative research. When I came back to academia after a career in the private sector, I observed that the qualitative researcher's academic career is punctuated by certain legitimating practices linked to doing 'good' qualitative research and being/becoming a 'good' qualitative researcher. In responding to the call of this special issue, I was minded to consider that while it is important to unpack 'good' qualitative research, there is something equally, if not more, important in understanding the power relations and identity issues involved in becoming and being a 'good' qualitative researcher. This is inextricably linked with how 'good' qualitative research is defined and by whom within our careers. Bazeley (2003: 269) identifies there is no one singular path, but illustrates these as including: a period of research training (commonly the $\mathrm{PhD}$ ); being appointed in an academic post; coping with teaching/research balance; growing and maintaining research alongside administrative roles; and (most obtuse) "achievement of established researcher status". Indeed, in my own experience, it seems that the process and accomplishment of transition between and within these example states is subject to a range of factors. Between and during these we occupy certain accepted identity states (Beech, 2011), for example, 'PhD student', 'early career researcher' and 'established researcher'. This may result in periods of uncertainty and insecurity to a greater or lesser extent within the overall career of an academic qualitative researcher.

In particular, in considering transitions, I was minded of van Gennep's (1960) theory of rites of passage, developed further in the work of Turner $(1969 ; 1974)$, who describes "a moment in and out of time" (1969: 96) as part of the experience of such rites that mark a change from one identity state to another. Van Gennep describes: a separation, where the person stops being one identity state, but is not yet another; a merge, where the person is becoming the next identity state; and an aggregation, where the person is legitimated as being the next identity state. The period from separation to aggregation is also termed 'liminality', framed as transition, being between states, a sense of suspension and temporary in nature. Whilst liminality may be positive in terms of movement, development, limbo implies a potentially problematic position to inhabit as there is no sense of accomplishment or aggregation. After all, Dante Alighieri characterised Limbo as the first Circle of the Inferno, those "held in suspense" who had lived 'good' lives but were not baptised (Alighieri, 2005 translation: 19). The role of others in the legitimation (baptism) or otherwise of liminars is particularly interesting to explore as it is others who 'baptise' us into our new identity states and "our knowledge is formed and shaped by our feelings about the world and the others with whom we interact and, thus, by our emotional relations to it and to them" (Burkitt, 2012: 469).

Following Shotter (1993), this includes not just questioning what to do in terms of 'good' qualitative research, but what to be in terms of a 'good' qualitative researcher. In an academic career, the moment of becoming the next state is often verified by colleagues who legitimate 'good' qualitative research in different ways. I consider two identity states along the path towards the "achievement of established researcher status" (Bazeley, 2003: 269). Compton and Tran (2017) have explored roles within PhD status and their contribution towards feelings of liminality or limbo, but I would argue that 'PhD student' is a defined and transitional liminal identity state. It has a clear point of separation (acceptance and registration of student status) and aggregation ('good' thesis and 'good' viva). The liminal 
period between these points is temporary and time-limited - crucially because it is in everyone's interests for students to complete this phase (for example, one of the key performance indicators of our School is the number of $\mathrm{PhD}$ completions within 4 years).

Contrasting with this is the 'early career researcher' identity state, defined as being "within their first 5 years of academic or other research-related employment allowing uninterrupted, stable research development following completion of their postgraduate research training" (Bazeley, 2003: 274). I do love the optimism in this definition, of 'employment allowing uninterrupted, stable research development' (see also the findings regarding time for research of Laudel and Gläser, 2008), but of more interest to me for the purpose of this paper is the timescale noted here. This too would suggest a clear end; however, I would suggest that, in my experience, whilst the starting point separation from ' $\mathrm{PhD}$ student' identity is clear, any point of aggregation towards 'established researcher' is predicated not on time, but on the unpredictability of publication and delivering impact indicators. It is also colleagues in the form of reviewers of my work who decide if it is 'good' enough or not. In this respect, any change in identity state is situated between myself and others (Thomassen, 2009; Beech, 2011).

\section{Conceptualizing liminality, limbo and identity states}

In its early anthropological definition, liminality refers to a temporally defined, relatively short period of time occurring after an individual has separated from one social identity state, with its associated norms and expectations, and before they take on another identity state, with a different set of associated norms and expectations. There are rites, that is, common and/or expected social practices, customs, conventions or acts, associated with the marking of the transition between states. These serve to differentiate the different moments of the process (Thomassen, 2009). Turner (1969) also unpacks liminality in forms according to the subject (individual, social group, society), time (moment, period, extended length), and space (place, area, country, region), which also indicates some of the useful complexities of the concept for making sense of individual and collective experiences in a range of social contexts.

Whilst liminality could be considered a time of absence, pause or waiting in some way, it can be more than this, rather being a time of activity in the learning or becoming of the next identity state. The liminar is very much between identity states, but it is a reactive time in which personal development takes place, individual and collective are closely connected, and there is "the sometimes dramatic tying together of thought and experience" (Thomassen, 2009: 14). There may well still be expected social practices, norms or obligations within the liminal time, but these are not linked to a clear identity state and it is this which characterises the 'in-between' nature of liminality. Leaving the liminal period is controlled by others; the liminar may know, or think they know, the rules of transition, but it is others who decide whether or not the liminar has achieved them (Thomassen, 2009). The decision in certain situations may be more subject to individual interpretation and interests than in other situations. The others are usually "elders" (Beech, 2011: 287), to whom the liminar may need prove themselves in some way in order to be endowed with the re-formed identity state that is both "meaningful for the individual and their community" (Beech, 2011: 287). The social environment has emerged from the direction and behaviours of those who are dominant within the field.

Bamber et al. (2017) further develop the theorising on the concept of liminality by distinguishing van Gennep's original definition as 'transitional liminality', with two other related concepts: permanent liminality, which "creates an enduring sense of being neither- $X$ nor- $Y$ or indeed of being both-X-and- $Y$ " (Bamber et al., 2017: 3); and limbo, which is "a fixed, 'trapped' state...not moving towards a threshold" (Bamber et al., 2017: 8). This 
distinction is important, as 'limbo' is frequently but imprecisely used in common parlance. My meaning for this paper matches Bamber et al.'s above, more like a suspension or stasis (Capps and Carlin, 2010) as opposed to the denotation of different states including a between-ness more similar to my understanding of liminality. This also echoes Dante's depiction of a place of neglect and abandonment, a place of both indifference at best and despondence at worst (Cantor, 1996).

\section{Context and positioning}

\section{My 'good' qualitative research?}

The analysis presented in this paper is both reflective (i.e. looking back on the 'past' of my $\mathrm{PhD}$ identity) and reflexive (i.e. being in the 'present' of my early-career researcher identity). Reflexivity is ontologically and epistemologically more complex than reflection because it involves a present and active consideration of the contexts in which knowledge is produced (Jorgensen, 2007) so as to understand what is happening within the research (Alvesson et al., 2008 ) and the knowledge it produces. It is grounded in the questioning of any potential for definitive knowledge of the social world (epistemological assumption) as any type of objective reality (ontological assumption) (Cunliffe, 2003). There is a weak subject/object distinction in my analysis because of the intersubjectivity of myself and others in constituting meaning and experience of 'good' qualitative research. The value of this is not in claims to basis in fact or truth, but in a provocation related to relatively common social experiences (Cunliffe, 2003).

Part of reflexivity is the requirement for consideration of the circumstances that have enabled my research to take place at all, particularly being aware of my own upbringing, education, employment), my location in fields (e.g. academia, business school, UK), my assumptions about the generation of knowledge, and social factors including resources (time, funding, supervisory support). In being reflexive, I acknowledge that, for example, the undertaking of a $\mathrm{PhD}$ candidature is in itself subject to struggle as to what a 'good' $\mathrm{PhD}$ should be; I am self-critical of my own work and recognise that my work will also be an object of critique by others in my fields. But why we do research, what are our interests, does not often feature in the sanitized presentation of our research. It is perhaps important to situate this paper with a brief description of where I have come from to this point. Previous identity states are relevant in relation to my own behaviours and actions within the layered contexts of my research and my broader life, albeit too much to include in detail within the scope of this paper. Qualitative research has been part of my purview for some time, with a 10 -year career in public and voluntary sector research and consultancy before re-entering academia as a research assistant. I received $\mathrm{PhD}$ funding a year later (separating me from 'research assistant' to become 'PhD student'). I was appointed as a lecturer towards the end of the final year of my $\mathrm{PhD}$ (separating from 'PhD student' to become 'early career researcher').

My thesis explores social actors' participation in two global forums, the World Economic Forum (WEF) and the World Social Forum (WSF), with the aim of creating more sustainable and equal worlds. Using Bourdieu's social theory, I propose that the research settings of WEF and WSF are enactments and representations of a global field of power. In this global field of power, social actors use global capital, a form of symbolic capital, to define the doxa of the field, that is, the taken-for-granted assumptions about issues of sustainability and inequality that require response, how they are defined and how they should be resolved. I discuss the tensions and dilemmas of social actors as they enact strategies within the field to promote conservation, succession and/or subversion of the doxa in relation 
to these issues of sustainability and inequality. The nature and extent of shifts in the global field of power as perceived by social actors is shown, with the aim that such shifts will support the creation of other, more sustainable and equal worlds. The empirical material gives participant impressions of their own involvement, which has implications for the identities, roles and activities of global social actors.

For my $\mathrm{PhD}$, I undertook 38 of what could be called interviews (e.g. Kvale and Brinkmann, 2009) with research participants. These can be categorised as such because they involved making a formal appointment via email, arranging to speak at a particular time/day using a particular method of face to face meeting, telephone or Skype interaction, for a specified length of time (driven by the research participant). 12 interviews were undertaken face to face, 8 through Skype audio only, 4 through Skype with video, and 14 over the telephone. Interviews ranged in time from 30 to 90 minutes, driven largely by the availability of each research participant in line with 'good' ethical practice (e.g. Economic and Social Research Council, 2012). Four additional research participants engaged with the research through email 'interviews'. These constitute interactions whereby research participants found it difficult to arrange a formal appointment to interact either because of their travel schedules, time differences or simply a preference to interact in this manner. These research participants were sent the list of discussion topics and they provided their responses to these via email. They follow a number of the conventions of a more 'traditional' interview, with questionanswer. However, the interaction was not 'live' or 'real-time', rather with delays and missing the interpersonal reactions that come with embodied interviewing. Despite this, the material is congruent with that of the more standard interviews described above. Six research participants offered comments, invited in the same way as other research participants, but, instead of agreeing to an interview of the formats described above, they simply provided some thoughts in response to my invitation email by reply.

\section{Writing this paper - 'good' qualitative research?}

There is wholehearted agreement that "we need to show readers how we came up with our interpretations, how we made mistakes and lucky guesses along the way to capturing other people's meanings" (Lichterman, 2017: 38); but, there is frequently a disconnect between what is published in methods sections of research articles and what is written as analysis of qualitative research processes/methodology (Donnelly et al., 2013). This paper is deliberately personal and emotion-laden (Dickson-Swift et al., 2009), which perhaps may be part of a visceral academic conversation about reimagining what identity transition could look like for future researchers. It places the researcher central to this examination of the research process (Humphreys, 2005). My narratives are a form of knowledge and may be a mode of producing knowledge (Bleakley, 2000), but in line with the epistemological and ontological assumptions outlined above, my focus is on provoking thought about research processes rather than knowledge objectives (Hayes et al., 2016). I intend to offer a self-reflexive (Hibbert et al., 2017) and confessional account (Bleakley, 2000) of 'good' qualitative research experiences in being a transitional liminar as a $\mathrm{PhD}$ student and in being an early career researcher as states in the becoming of an established researcher. My fears are explored that I am not currently in a transitional liminal identity state, but that I am at risk of limbo because of the reliance on the judgment of others to legitimate me. Writing this paper is also a risk and it was nearly not submitted.

Using personal journals throughout my research, I kept notes of: the decisions I made regarding the selection of empirical material and research participants; my experiences; and thoughts as the research progressed (Lincoln and Guba, 1985; Cunliffe, 2004). I also kept methodological notes as to why and how actions, events or things said/unsaid were of interest 
and problems encountered (Haynes, 2012). Note-taking was regularly undertaken throughout the research, not only as a recording function but it also had transformative and interpretive functions for me as I produced and analysed the empirical material (Cunliffe, 2004). Notes were written down physically, categorised as individual prompt words, full reports, quotes and paraphrases, and records of observations, theories and methodological points (Haynes, 2012). Outside of the research and in my life as a lecturer, I still keep notes and jottings of my thoughts, reactions and experiences, continuing to "liv[e] life as inquiry" (Hayes et al., 2016: 129). All the notes taken throughout my research experiences have enabled me to reflect on myself as part of the setting of that moment, affecting it and being affected by it (Cunliffe, 2003), as well as when interpreting the material at different stages of the research. This was also important for my personal and professional development as an academic researcher, as a 'good' qualitative researcher, understanding also my engagements with 'good' qualitative research. These are not as systematic as the research journals, but they still reflect unsettling, ambiguous, incomplete expressions and subjective identities (Hayes et al., 2016). Donnelly et al. (2013) speak to the messiness of doing research and I present an account of my mess here. All of this is part of asking ourselves "what in hell do we think we are up to?" (Alvesson, 2003: 177), the researcher's "willingness to challenge and revise one's initial position" (Alvesson, 2011: 5).

I aim to offer a reflexive account, that is, unsettling myself and my role within a set of academic practices, but also unsettling the set of academic practices themselves by questioning them based on my own experiences (Cunliffe, 2009). It is both retrospective (reflective) and present to be an ongoing reflexive analysis of my own situation (Pritchard, 2011), organised through a review, reflection and reflexive unsettling of my experiences. There are difficulties in representing the self (Haynes, 2011), confessional modes of writing reveal vulnerability (Schultze, 2000) and they also need to be reflexively questioned as they can be a construction of a particular form of self despite being presented as a form of authentic truth (Bleakley, 2000). Acknowledgement of this implies that there should be less expectation of finding some sort of singular truth or unifying theory in the empirical material, but rather a consideration of the relationship between researcher, researched and in the pursuit of new knowledge and understanding. Whilst 'good' qualitative research may mean a comprehensive approach, it feels like this cannot be guaranteed by the researcher, no matter how 'good'. So, borrowing from Humphreys (2005: 843), through the following sections, I invite you to "participate in my life drama" by inspiring your own reflections.

\section{Being, becoming... or not}

As illustrated in the starting thoughts above, I have been considering my academic identity states in relation to transitions and liminality. Identity states in the academic career have been identified in different ways, for example: apprentice; colleague; master; then member of the elite (Laudel and Gläser, 2008: 390). I am not sure that there is as clear a separation or linearity between three phases of transition as Van Gennep (1960) proposed (preliminary, transitional, incorporation) because "changes in identity imply changes in the meanings associated with a person, and meanings are not simply located in the 'subjects' but in the relationship between the individual and the organization (or society)" (Beech, 2011: 288). Some of these states are more clearly demarcated than others; for example, 'apprentice' could relate to being a PhD student, 'colleague' could be early career researcher and beyond.

Being a PhD student in becoming a 'good' qualitative researcher 
Undertaking a PhD can be considered the entry-level requirement in becoming a 'good' qualitative researcher. In doing a $\mathrm{PhD}$, we must develop an active and independent approach towards research, which can feel isolated and unsettled. There is much written about being and becoming a 'good' researcher in the field (Fontana and Frey, 2005; Brinkmann, 2007; Kvale and Brinkmann, 2009; Giampapa, 2011; Donnelly et al., 2013), our research can be designed with a set of general features of 'a good qualitative research study' in accordance with the rules of being and becoming a 'good' qualitative researcher ('the researcher should') and 'good' qualitative research ('the study should') (Seale et al., 2007). Here I describe my experiences of being in the transitional liminal identity state of being a PhD student as part of becoming a 'good' qualitative researcher.

In considering being a PhD student as part of becoming an established academic, it could be argued that this is not liminal because there is certainty of the common and/or expected social practices to be undertaken in order to achieve the doctorate. This includes designing and delivering an autonomous and independent piece of 'good' research.

Candidates prove themselves to their elders through the examination of the thesis and through the viva. Reflecting, I can see how this identity state had a definite starting point of separation and I could always see the end point of aggregation. In line with the traditional theorisation of liminality, the identity state of $\mathrm{PhD}$ student is time limited (usually four years maximum). Therefore, the liminality experienced was always recognised as temporary. However, this does not mean that the liminal state is not characterised by uncertainty and in-betweenness in terms of moving towards the rite of legitimation through the thesis and viva. The process of being a $\mathrm{PhD}$ student has been problematized, for example, being 'autonomous' and 'independent' is situated in masculinised, objectivist privileging of knowledge and its creation (Johnson et al., 2000), the PhD includes "stories of trauma", the experience of which is "some kind of badge of honour" (Mewburn, 2011: 323). Doing a PhD is a clearly defined rite of passage (Van Gennep, 1960; Turner, 1969) and, while my experiences discussed within this paper are perhaps not quite as vividly negative as these descriptions, I suggest that they are characterised by uncertainty that I feel relates to being a liminar. These are explored as follows.

I designed my $\mathrm{PhD}$ research in response to elements of the 'recipes' of good qualitative research, executed and performed it according to the rules and norms of 'good' qualitative research. But this is not to say that the experiences in learning the craft of 'good' qualitative research were always comfortable and easy to negotiate and this reveals the nature of the liminal experience; I had to make decisions and act without certainty and in the context of contradiction, some of which may have compromised the execution of 'good' qualitative research in the judgment of research participants, supervisors and examiners. A particular situation that I felt was problematic was the following instance, as described in three separate journal entries.

One interviewee has agreed to speak as long as I am also speaking to [people from a particular organization] - not sure how I feel about this - I replied to say I haven't as yet but if there are particular people I should, let me know - no response. I had been considering two contacts anyway... but no guarantees they will speak and I'm more interested in participants than employees anyway. Feeling a bit forced. But is it exclusive if I don't at least try?

He [same interviewee] has made an introduction for me, so that is helpful, means I have to do this - not sure how I feel about being 'forced' to do this?!! But ethically I have to go ahead with this. 


\begin{abstract}
Was initially quite worried about this given the way it was suggested to me (or imposed on me!!) Was more reassured when it was rescheduled a few times, made me think that he wasn't desperate to see what I was up to or trying to stop me in some way...He was very interested in me and my background... made me feel quite valued compared to other interviews who haven't seemed particularly bothered!
\end{abstract}

From my perspective, whilst I tried to have contact with a range of individuals and have discussions with them in some depth, presence and absence in my work is subject to the restrictions of chance and choice, as well as the silencing of some because of the inability to speak the respective others' language. My interests were driving the research. I was in need of participants to contribute in order for me to gain my $\mathrm{PhD}$ qualification, but also participants were driven by their own agendas to participate or not, or (in this case) engineering the participation of others. This particular experience highlighted the extent to which interviewees may have their own agendas, as well as my inability to influence their willingness (or not) to share, articulate or perform the interviewee role as expected. To maximise participation, I followed their willingness and availability, sidelining my own concerns, but being a 'good' researcher in my conduct. As a liminar, I certainly had the social norms, conventions and expectations of 'good' qualitative research to help me in my decision making; however, these only help so far in the moment of action where my "agency is pushed to the forefront" (Thomassen, 2009: 20).

Another experience noted in my journals made me think about the notion of lying in research and how this affects the value judgment of 'good'.

This interviewee knew that I had met a colleague - who had recommended him. He asked me if the other had talked about particular aspects of the WEF operation - I said no when in fact he had. Implications of this? Protecting confidentiality of original interviewee but lying to this one?

This illustrates the difficulty of behaving ethically as a characteristic of 'good' qualitative research. Am I a 'good' qualitative researcher even though I lied to my participants, and certainly was not transparent about this? Despite considering confidentiality, which would allow me not to say anything that would breach the confidentiality of the interviews, lying would seem a separate and conflicting ethical issue that is not easily reconciled. As a liminar I had to negotiate a course of action that I could live with as being 'good' in the presence of somewhat contradictory positions (Giampapa, 2011).

Rites of passage and liminality are frequently imbued with emotion (Van Gennep, 1960; Turner, 1969), as are other social practices that affect our identity (Szakolczai, 2009; Ybema et al., 2011). In terms of my emotions, undertaking 'good' qualitative research has, at times, felt isolated with a requirement for extreme emotional control, as shown in the following examples from my journals.

A little brusque in the conversation, he wasn't really initially listening to my questions, was predicting them and directing me to website rather than giving me his experiences. This lessened as the conversation progressed-very difficult when time is limited - I could feel the assumptions being made, which I could counter to some extent but only as time went on so really only the second half of the conversation that felt fully engaged

An older man, tried to demonstrate absolute respect despite disagreeing a lot with what he was saying, interesting and quite 'traditional' view of what trade should 
be. Limited recognition of or interest in the social implications. First interview that has made me cross, I had to bite my tongue, would have been hard to hide if it had been face to face

Here I was lying again, as I was masking how I was really feeling. In all my contacts I was very conscious of my perception of myself in relation to my research participants and mostly felt that I was taking a submissive position, frequently feeling that I was intruding on their time and social space, despite the fact that they had all volunteered to participate. This intrusion was more obvious in some interviews than others, with comments in my journals including "I felt I was an inconvenience in his day", "not very engaging" and "typing during conversation at times - distracted? Not fully paying attention?!" I was not in control of the exchange process and would not expect to be, but this felt like I was not a 'good' qualitative researcher because the research participants were not particularly engaged in our discussions. As a liminar, I just had to learn to deal with this (get over it?) despite it being unsettling. I cannot claim that the interactions with my research participants offer anything other than a snapshot insight into the areas discussed. Every expression of research is an interpretation of a set of moments as experienced and constructed by me, my research participants and the artefacts reviewed, i.e., not just me. There is nothing wrong with a snapshot, but it feels so partial and manipulative and certainly not 'good' research, but a stressful experience for me as described in my journals.

Decision not to chase any more interviews and start analysing. If people come back, will arrange but not going to actively pursue. Quite relieved. Found interviewing stressful. Some easier than others but never shook the feeling of tension when an interview was due. Feeling of excitement when arranged, and accomplishment when done, but didn't enjoy the actual experience that much...Frequently felt that I was being somehow insincere as I was performing in order to get data. Frequently felt unable to say how I really felt or offer my own opinions for fear of alienating the respondent.

The decision made was nothing to do with saturation or any of the other institutionalised and accepted reasons for stopping interviewing in 'good' qualitative research. It was purely about my own stress and my own relief. A 'good' qualitative researcher? Perhaps not. Whilst it is a representation in good faith, the production of the thesis did, at times, feel like a process of exclusion of significant amounts of material, themes and expressions, not a comprehensive one. I have found this brutal (described as 'hatcheting' in my journals), driven by word limit and other conventions of the candidature. I have reminded myself that future papers may emerge so that the value of the material is not lost, but some of the interrelationship between different themes in the material has been reduced. This is something with which I feel uncomfortable as it feels partial and incomplete, as well as being something constructed for my own use and gain (not theirs). I wish I could claim otherwise. At the time maybe I expected the thesis to be of more impact, but, in complete honesty, I was instrumentally focused on producing something that would pass examiner scrutiny. Perhaps my struggles to publish work from it demonstrate my and its weakness in being any sort of instrument for change?

As a liminar, I was actively learning how do to 'good' qualitative research towards becoming an independent researcher. I emerged from the liminal identity state because I was considered 'good' enough to pass my viva exam by two significant elders and my research was considered 'good' enough to be completed as a thesis, enabling me to move into the identity state of the early career researcher. I feel this is a less clearly defined rite of passage 
(Van Gennep, 1960; Turner, 1969), which I think presents a set of risks for me. The two most significant and connected aspects (to me, so far) of transitioning from 'good' $\mathrm{PhD}$ student to 'good' early career qualitative researcher is: 1) the requirement to publish, which requires peer relationships with colleagues who review our work and judge it 'good' for publication; and 2) demonstrating impact, particularly in international terms, also judged in part by our academic colleagues. The implications of these are explored in the following sections.

\section{Being an early career researcher in becoming a 'good' qualitative researcher?}

The next identity state of 'early career researcher' (ECR) is where I think the importance of liminality and our academic identity become particularly important to explore. My current position as an ECR, whilst also liminal, is less clear and more uncomfortable because meeting the expectations of those who can legitimate me out of this identity state is much harder. As such, we gain some credibility from the doctorate, which is soon minimised as we negotiate being an 'early career researcher'. There is a literature on early career research that explores the movement from supported to self-determining research, with "the early career phase...considered as containing a status passage from the apprentice to the colleague state of their career" (Laudel and Gläser, 2008: 387). There are challenges associated with this period, including questioning our own abilities, not feeling valued by colleagues, and endeavouring to develop our 'fit' to make a contribution (McAlpine and Amundsen, 2015). Example characterisations of early career researchers include one that shows us as having deficits, for example: lacking contacts; credibility; and knowledge of university life. Another shows us in a developmental state, for example; as developing our profession; progressing through our career (Hemmings and Kay, 2010).

In this respect, unlike the identity state of ' $\mathrm{PhD}$ student', there is a lack of clear, overt and standardised ritual (Beech, 2011). However, I also believe being an early career researcher constitutes a liminal identity state in becoming an established researcher, albeit as a different form of liminality. As introduced in my starting thoughts, a distinction has been shown between types of liminality. This includes one type with clear temporal boundaries marked by clear rites as transitional liminality - "a sense of being not-X-anymore-and-not- $Y$ yet" (Bamber et al., 2017: 3) - where there is a clear sense of movement towards something. Another type can be considered perpetual, where the liminars are in-between identity states for an extended period of time (Ybema et al., 2011), a state of perpetual manufacture. This is potentially positive as the period can be considered "a revolving doorway, rather than a threshold" (Bamber et al., 2017: 7), which enables liminars to occupy an identity state on the margins, a potentially powerful position for creativity and social change. As such, the identity state of 'early career researcher' may represent a more longitudinal or perpetual liminality (Beech, 2011; Ybema et al., 2011), or, potentially, the risk of being in a state of limbo.

As an early career researcher, I may have to reconcile that the activities in which I invest my time, the expertise that I grow and the experiences that help the growth process may convince some elders and alienate others. I was inspired by Hayes et al.'s (2016:129) approach, that "we are trying to find ways to establish our own academic credentials while paying attention to the learning we have experienced, which has enabled us to develop our voices, yet which may have condemned us to struggle with our subjectivities in an environment where even radical perspectives have a powerful grammar and set of taken-forgranted assumptions". There is a wider range of others to whom I feel I need to prove myself, both in my organisational context (school, university) and my wider social scientific community (Laudel and Gläser, 2008). Ending the liminal period is in the control of others, as with the $\mathrm{PhD}$ student identity state, but in this state it is particularly colleagues who act as reviewers, editors and/or impact assessors; "so the imagination of the judgement and 
evaluation of the other is crucial in terms of how we perceive ourselves to appear in their thoughts, something which is done little justice through the simple metaphor of a 'looking glass self"' (Burkitt, 2012: 466). Whilst there may be no ambiguity in the requirement (publishing, impact), there is uncertainty in the achievement of these outcomes (subject to the decisions, the baptism, of others). So, although I know these are the requirements, that the liminal identity state of betweenness is perhaps bounded by the rites of publication and impact, this is not enough to help me achieve the requirements - I cannot transition out of the state of betweenness until others deem my work 'good' enough. For example, I know what I have to do (publish), yet I do not know what I have to do to do this, or I do know what to do according to the various advice and guidance available, but why am I not convincing reviewers?. This is the present and the following sections offer details on my experiences of this.

'Good' research involves learning to engage with other academics in our work independently but then submissively. Being an early career researcher feels constituted by learning the craft of writing to persuade, following the rules of each journal and its associated reviewers, and this marks a shift in the focus for 'good' qualitative research from executing to presenting. Whilst the thesis also involved presenting at conferences and within my institution, and writing to persuade through the thesis, I was acting to prove my ability as an independent researcher, to be legitimated by a small audience - supervisors and examiners and $\mathrm{PhD}$ developmental conference tracks.

\section{Being an early career researcher involves presenting and writing to a larger and more complex audience of reviewing colleagues, who seem to be largely a cross, intolerant and unsupportive set of people and to whom I ought to be submissive as a new entrant to their very competitive field. Too harsh? Perhaps. A massive sweeping generalisation? Definitely. But that's what happens when you get 3 rejections in a week.}

Knowledge is a process not a product, but we have to produce products or outputs and "the qualitative researcher through socialisation into the prevailing academic discourse... is encouraged to take on the "omniscient voice of science, the view from everywhere", (Johnson, 2001: 57). I have felt a tension in academic discourse, within qualitative research as well as more obviously between qualitative and quantitative disciplines, between positions that express the need for "a researcher to consider and present her work in an omniscient and impersonal tone" (Johnson, 2001: 53) and those that support and value first-person accounts and reflexivity. There seems to be more certainty and judgment on the part of those who see 'good' qualitative research as a singular formula - for example, a recent reviewer (not of this paper, I might add...) commented that I should construct my methodology with " $a$ description of the interview method", as if 'the interview method' was one accepted and universal thing. Being liminal involves the negotiation of these tensions and becoming a qualitative researcher in such a way that I can justifiably claim as 'good'.

The rite of constructing 'good quality' outputs can feel like the requirement to be a publishing machine, not just in volume but in the right journals according to academic journal guides, as compiled by certain academic colleagues (e.g. Chartered Association of Business Schools, 2015; Ormans, 2016). It may be that our research fits with the scope of a range of journals, but as a business school scholar, 'good' is indicated by particular journals, publishing in which offers legitimation. 'Good' articles must tell a good story that is gripping and convincing the reader and we must be disciplined (controlled?) to follow the norms and conventions that our elders expect. However, whilst there may be clarity of what should happen to move out of the liminal identity state of 'early career researcher, there is still 
difficulty in doing so. For example, our publications must make a theoretical contribution, accounting for our research in a systematic and rigorous way and presenting analysis according to orders of concepts (Gioia et al., 2013).

This is where I need to get to, this 'theoretical realm' and there I will be a good researcher. This feels so straightforward yet so out of reach.

So, in theory, I know what I need to do to move through this liminal phase and become aggregated as an established researcher in terms of publishing and having impact in my research. For the Academy of Management Journal, for example, pieces should demonstrate "comprehensive, personal and transparent methods" (Bansal and Corley, 2012: 510) amongst other requirements. Yet, it feels out of reach and I feel unable to progress within/beyond this in-between state. Knowing what to do does not equal knowing how to get there, because one's research has to be 'good' enough, one has to be 'good' enough. It has felt that it is important to follow the 'mainstream' rules in order to have a chance of publishing, but my own work is still not published. If "[i]n practice research glides, more or less consciously, between two or more of these levels: the handling of the empirical material, interpretation, critical interpretation and reflections upon language and authority" (Alvesson and Sköldberg, 2000: 248), I certainly never felt like this - I would expect 'gliding' to feel comfortable rather than feeling in a fairly constant state of unworthiness and relative stupidity. We must be confident and convincing about our work, yet authentically I feel doubt, constant inbetweenness and anxiety at worst (Szakolczai, 2009). My qualitative research is not 'good' enough, I am not 'good' enough, reflecting the liminal identity state.

As well as the rite of publishing, with its challenges for accomplishment as outlined above, I feel that the liminal identity state of early career researcher is also bounded by the even more esoteric rite of research impact. Again, it would seem that I do have the rules and conventions that would help me achieve impact. For example, one way in which 'good' research (including qualitative research) in the UK is judged according to impact is through the Research Evaluation Framework (2011 updated 2012), which defines impact "as an effect on, change or benefit to the economy, society, culture, public policy or services, health, the environment or quality of life, beyond academia" (Research Evaluation Framework, 2011). I struggle with this, as noted in my journals.

I find reminiscences fulfilling and comforting at this stage in my education and career. They reinforce my confidence in what I had learned previously as well as instilling a feeling of inspiration to draw more and deeper on past elements of my learning journey, rather than consigning them to something complete and ended. I feel envious of those whose research seems to be less restricted by conventions than mine is. I feel envious of those whose research presents in a more focused way than mine ever has. I spend much time feeling at a constant deficit.

Notions of impact according to expertise are problematic because: it may be a limited group who can operate in this way (unlikely to include early career researchers?); 'international expertise' may be narrowed according to the interests of this group; and international problems may be defined and solved by those who have an international expert identity may be demonstrably influential towards a range of policy, economic and business practices (Pries, 2013; McKenna et al., 2015) making it important to know more of who is participating, why and how. I feel challenged by this in becoming a 'good' qualitative researcher, as noted in my journals. 
Not deliberate, but I feel very submissive, this person is an expert, very warm and welcoming yet I feel humble and unworthy. I am intimidated by the situation - not caused by the participant, my own reaction - how do I control this? Worried about asking the 'right' questions

A personal fear is that ineffective transition beyond would potentially lead to a state of limbo whereby the novice, developmental and perhaps marginalized position occupied (Turner, 1974) as an 'adequate' qualitative researcher is the continuing identity state. This may be materially represented by a move from teaching and research to teaching and scholarship contract - I may not be a 'good' qualitative researcher but I may be a 'good' teacher and scholar...so is there another identity state that I am moving towards, rather than the one I have worked so hard to accomplish? The risk of no legitimation is apparent, where "some academics remain confined to an early career 'space' and cannot, or find it very difficult to, make the transition from apprentice to colleague or dependent to independent academic" (Hemmings and Kay, 2010: 564). In this case, whence liminality? I feel that I am not 'good' enough and never will be - am I stuck in limbo? This implies being trapped and static- it is not enjoyable, it is without potential (Bamber et al., 2017). It is possible that a myth of liminality is propagated to maintain hope, as without it we would be thoroughly miserable. As introduced earlier, the end of the liminal period is dependent on others, elders, to legitimate us in our next identity state. But without this, in Dante's words "The world accords them not the least renown. Pity and justice scorn them equally" (Alighieri, 2005 translation: Inferno III 46-51).

\section{Concluding thoughts}

This paper is based on my subjective experiences of being and transitioning between the identity states (Beech, 2011) of PhD student and early career researcher, discussing and reflecting on issues of what constitutes 'good' qualitative research practice. Completing the $\mathrm{PhD}$ is one such practice and it would seem that the process of completion is also subject to certain rules of 'good' qualitative research that students have to learn and execute appropriately, almost as an apprentice position (Park, 2005; Laudel and Gläser, 2008; Hemmings and Kay, 2010). I offer an account of the challenges involved in learning the craft (Kvale and Brinkmann, 2009; Cunliffe, 2011), executing 'good' qualitative research, being and becoming a 'good' qualitative researcher. I illustrate some common rites of passage (Van Gennep, 1960; Turner, 1969) and draw on the theories of liminality to understand the feelings of in-betweenness and the fears experienced during this indeterminate time: "the term 'liminality' helps us to understand that such major events literally and effectively transform the very mode of being of those individuals involved" (Szakolczai, 2009: 158).

The paper is presented as a way to reveal some of the questions and problems with conceptualizing 'good' qualitative research, particularly suggesting an intrinsic link with identity states involved in becoming/being a 'good' qualitative researcher and experiences thereof. Planning 'good' qualitative research is one thing, executing 'good' qualitative research is entirely another, as is publishing 'good' qualitative research and having impact from 'good' qualitative research. I feel that different experiences of liminality characterise the identity states of being a 'PhD student' and being an 'early career researcher' towards becoming an 'established researcher' (Bazeley, 2003). 'PhD student' represents transitional liminality, and 'ECR' has potential for not transitional liminality but the risk of a fixed limbo state without ever becoming an 'established researcher'. Whilst, in my experience, the identity state of $\mathrm{PhD}$ student is relatively delineated with clear rites to the identity state of 'early career researcher', this latter liminal identity state is potentially an interminable 
transition - a limbo rather than a liminal state (Bamber et al., 2017). It seems that there is potential for one's career to stall despite doing 'good' qualitative research; there is a gap between this and being a 'good' qualitative researcher. A continual state of becoming implied by perpetual liminality is acceptable, perhaps because there are senses of achievements throughout, accomplishment rather than completion (Szakolczai, 2009), whereas limbo is less acceptable because it implies stasis or 'stuckness'.

There do seem to be some rites, that is, common and/or expected social practices, customs, conventions or acts that relate to the crafting and execution of 'good' qualitative research. These are socially produced in the setting we call 'academia' and they affect my legitimation (or not) as a 'good' qualitative researcher. How we progress as judged by our elders decides whether we accomplish the next identity state or not, for example "through a system of rewards and punishments in which the $\mathrm{PhD}$ is awarded or not, in which the journal article is published or not, in which promotion is granted or not" (Johnson, 2001: 58).Some rites may seem 'easy' and 'clear' to facilitate participation and/or production, but I am subject to power relations that mean my legitimation is intermingled with the behest of others ( $\mathrm{PhD}$ examiners, publication reviewers), making progression from liminar to academic less predictable. Judgments of 'good' occur in relation to our interactions with research participants (in the field) and colleagues as elders (through our writing and other interactions) - this indicates the significance of others, that there is no way for us to become without others as playing a part in the becoming. They represent both the risk of limbo and the possibility of becoming.

These in turn mark points of progression (van Gennep's (1960) separation and reaggregation) to different identity states in a researcher's career. However, the period between these rites (van Gennep's (1960) liminality) may be difficult to determine and which may contribute towards a continual, interminable state of becoming a 'good' qualitative researcher. We are left to our own devices in liminal periods - social guidance is not completely absent, but it is up to us how to deal with this and it can be confusing and disturbing. Understanding this as in-betweenness may help reconcile where we are, who we are and how we are transitioning or not (Beech, 2011). Although these rites may, indeed should, represent the return of some form of structure and sense of achieving reaggregation, what may happen is that there is not enough to legitimate me as a 'good' researcher, particularly during the early career identity state.

It seems to me that the extent to which $\mathrm{PhD}$ students and early career researchers can be legitimated and developed in their career in qualitative research may be affected according to their adherence to certain normative 'good' practices as defined by established researcher colleagues. It is a contradiction that I both conform to and shape the construction of 'good' qualitative research and a 'good' qualitative researcher through adherence to implicit and explicit messages from colleagues and publications - I benefit from playing the game to become legitimate, yet I feel that I am yet to be legitimated. Beyond the $\mathrm{PhD}$, in being an early career researcher, 'good' qualitative research is linked with the publication of outputs and a new set of rules to negotiate. In experiencing these qualitative research practices, I felt that there were times of being and times of becoming, linked to transitions between identity states marked by my elders (Beech, 2011). Proving myself along the way has come from demonstrating independence $(\mathrm{PhD})$ and demonstrating submission to others (early career researcher).

The point of considering all of these issues in relation to re-conceptualising good research in organisation and management studies is that being a $\mathrm{PhD}$ student and being an early career researcher are common identity states. An analysis of the intersection between learning and executing the craft of academic qualitative research according to received wisdom is provided to ground our understanding of the importance of recognising different 
ways to define 'good' research in making transitions to being a 'good' researcher. There may be a disconnect between the process of doing 'good' research and the ways in which this is recognised in output form. This means that 'good' qualitative research intersects me and others, with multiple interests influencing the construction of the legitimate identity state of the 'good' qualitative researcher. 'Good' research expectations shift or morph according to who sits in judgment. I am not sure we can prepare $\mathrm{PhD}$ students for clear and definite transitions throughout an academic career, but perhaps what we can do is identify and talk more about liminal experiences and the in-betweenness felt. The judgment of goodness, for someone starting out in their academic career, is made by our elders, as would be expected, but at some point we have to be judged 'good' enough ourselves to allow transition from liminal identity states to the legitimated and accomplished identity state of "established researcher'. Elders, as the elites and established researchers in the academy who are in the position to legitimate, 'baptise', early career researchers can perhaps also think reflexively about their own practice in relation to those who are becoming. I certainly will, should I ever become one.

\section{Acknowledgements}

I am grateful for the time spent by the editors and two anonymous reviewers, their extensive and thought-provoking comments were constructive and invaluable in helping me to improve the paper. 


\section{References}

Alighieri D. (2005 translation) The Divine Comedy: Inferno, London, UK: Hesperus Press Limited.

Alvesson M. (2003) Methodology for close up studies-struggling with closeness and closure. Higher Education 46: 167-193.

Alvesson M. (2011) Interpreting interviews, London: Sage.

Alvesson M, Hardy C and Harley B. (2008) Reflecting on Reflexivity: Reflexive Textual Practices in Organization and Management Theory. Journal of Management Studies 45: 480-501.

Alvesson M and Sköldberg K. (2000) Reflexive Methodology: New Vistas for Qualitative Research, London: SAGE.

Bamber M, Allen-Collinson J and McCormack J. (2017) Occupational limbo, transitional liminality and permanent liminality: New conceptual distinctions. Human Relations 70: $1514-1537$.

Bansal P and Corley K. (2012) Publishing in AMJ-Part 7: What's different about qualitative research? Academy of Management Journal 55: 509-513.

Bazeley P. (2003) Defining'early career'in research. Higher Education 45: 257-279.

Beech N. (2011) Liminality and the practices of identity reconstruction. Human Relations 64: 285-302.

Bleakley A. (2000) Writing with invisible ink: Narrative, confessionalism and reflective practice. Reflective Practice 1: 11-24.

Brinkmann S. (2007) The Good Qualitative Researcher. Qualitative Research in Psychology 4: $127-144$.

Burkitt I. (2012) Emotional reflexivity: Feeling, emotion and imagination in reflexive dialogues. Sociology-the Journal of the British Sociological Association 46: 458-472.

Cantor PA. (1996) The uncanonical Dante: The divine comedy and Islamic philosophy. Philosophy and Literature 20: 138-153.

Capps D and Carlin N. (2010) Living in limbo: Life in the midst of uncertainty: Wipf and Stock Publishers.

Chartered Association of Business Schools. (2015) Academic Journal Guide 2015. Available at: https://charteredabs.org/academic-journal-guide-2015/.

Compton M and Tran D. (2017) Liminal space or in limbo? Post Graduate Researchers and their personal pie charts of identity. Compass: Journal of Learning and Teaching 10.

Cunliffe AL. (2003) Reflexive inquiry in organizational research: Questions and possibilities. Human Relations 56: 983-1003.

Cunliffe AL. (2004) On becoming a critically reflexive practitioner. Journal of Management Education 28: 407-426.

Cunliffe AL. (2009) Reflexivity, learning and reflexive practice. In: Armstrong SJ and Fukami CV (eds) The Sage handbook of management learning, education and development. London: Sage, 405-418.

Cunliffe AL. (2011) Crafting qualitative research: Morgan and Smircich 30 years on. Organizational Research Methods 14: 647-673.

Dickson-Swift V, James EL, Kippen S, et al. (2009) Researching sensitive topics: qualitative research as emotion work. Qualitative Research 9: 61-79.

Donnelly PF, Gabriel Y and Özkazanç-Pan B. (2013) Untold stories of the field and beyond: narrating the chaos. Qualitative Research in Organizations and Management: An International Journal 8: 4-15.

Economic and Social Research Council. (2012) Framework for Research Ethics. Available at: http://www.esrc.ac.uk/about-esrc/information/research-ethics.aspx. 
Fontana A and Frey JH. (2005) The Interview: From Neutral Stance to Political Involvement. In: Denzin NK and Lincoln YS (eds) The SAGE handbook of qualitative research. 3rd ed. Thousand Oaks: Sage Publications, 695-727.

Giampapa F. (2011) The Politics of "Being and Becoming" a Researcher: Identity, Power, and Negotiating the Field. Journal of Language, Identity \& Education 10: 132-144.

Gioia DA, Corley KG and Hamilton AL. (2013) Seeking qualitative rigor in inductive research: Notes on the Gioia methodology. Organizational Research Methods 16: 1531.

Hayes L, Hopkinson C and Taylor AG. (2016) Problematising qualitative research in organisations: Three voices, three subjectivities, three struggles. Qualitative Research in Organizations and Management: An International Journal 11: 127-146.

Haynes K. (2011) Tensions in (re)presenting the self in reflexive autoethnographical research. Qualitative Research in Organizations and Management: An International Journal 6: 134-149.

Haynes K. (2012) Reflexivity in Qualitative Research. In: Symon G and Cassell C (eds) Qualitative organizational research : core methods and current challenges. Los Angeles ; London: SAGE, 72-89.

Hemmings B and Kay R. (2010) Research self-efficacy, publication output, and early career development. International Journal of Educational Management 24: 562-574.

Hibbert P, Callagher L, Siedlok F, et al. (2017) (Engaging or Avoiding) Change Through Reflexive Practices. Journal of Management Inquiry: 1056492617718089.

Humphreys M. (2005) Getting personal: Reflexivity and autoethnographic vignettes. Qualitative Inquiry 11: 840-860.

Johnson H. (2001) The PhD student as an adult learner: using reflective practice to find and speak in her own voice. Reflective Practice 2: 53-63.

Johnson L, Lee A and Green B. (2000) The PhD and the autonomous self: Gender, rationality and postgraduate pedagogy. Studies in Higher Education 25: 135-147.

Jorgensen MW. (2007) Reflexivity and the Doubles of Modern Man: The Discursive Construction of Anthropological Subject Positions. Critical Discourse Analysis: Theory and Interdisciplinarity. Basingstoke: Palgrave Macmillan, 63-82.

Kvale S and Brinkmann S. (2009) Interviews: Learning the craft of qualitative research. California, US: SAGE.

Laudel G and Gläser J. (2008) From apprentice to colleague: The metamorphosis of early career researchers. Higher Education 55: 387-406.

Lichterman P. (2017) Interpretive reflexivity in ethnography. Ethnography 18: 35-45.

Lincoln YS and Guba EG. (1985) Naturalistic inquiry, Beverly Hills, Calif.: Sage Publications.

McAlpine L and Amundsen C. (2015) Early career researcher challenges: Substantive and methods-based insights. Studies in Continuing Education 37: 1-17.

McKenna S, Ravishankar MN and Weir D. (2015) Critical perspectives on the globally mobile professional and managerial class. critical perspectives on international business 11: 118-121.

Mewburn I. (2011) Troubling talk: Assembling the PhD candidate. Studies in Continuing Education 33: 321-332.

Ormans L. (2016) 50 journals used in FT Research Rank. Available at: https://www.ft.com/content/3405a512-5cbb-11e1-8f1f-00144feabdc0.

Park C. (2005) New variant PhD: The changing nature of the doctorate in the UK. Journal of Higher Education Policy and Management 27: 189-207.

Pries L. (2013) Ambiguities of global and transnational collective identities. Global Networks 13: $22-40$. 
Pritchard K. (2011) From "being there" to "being [...] where?": Relocating ethnography. Qualitative Research in Organizations and Management: An International Journal 6: 230-245.

Research Evaluation Framework. (2011) Impact Case Studies Frequently Asked Questions. Available at: http://impact.ref.ac.uk/CaseStudies/FAQ.aspx.

Research Evaluation Framework. (2011 updated 2012) Assessment framework and guidance on submissions.

Schultze U. (2000) A confessional account of an ethnography about knowledge work. MIS quarterly: 3-41.

Seale C, Gobo G, Gubrium JF, et al. (2007) Introduction: Inside qualitative research. In: Seale C, Gobo G, Gubrium JF, et al. (eds) Qualitative Research Practice. London: SAGE, 1-12.

Shotter J. (1993) Conversational realities: Constructing life through language: Sage.

Szakolczai A. (2009) Liminality and experience: Structuring transitory situations and transformative events. International Political Anthropology 2: 141-172.

Thomassen B. (2009) The uses and meanings of liminality. International Political Anthropology 2: 5-27.

Turner V. (1969) The Ritual Process, Harmondsworth, Middlesex: Penguin.

Turner V. (1974) Liminal to liminoid, in play, flow, and ritual: an essay in comparative symbology. Rice University Studies 60: 53-92.

Van Gennep A. (1960) The rites of passage, London: Routledge and Kegan Paul.

Ybema S, Beech N and Ellis N. (2011) Transitional and perpetual liminality: An identity practice perspective. Anthropology Southern Africa 34: 21-29. 